\title{
Прогнозирование эффективности тоцилизумаба и ритуксимаба при ревматоидном артрите
}

\author{
М.В. Волкова \\ Белорусская медицинская академия последипломного образования, г. Минск, Беларусь
}

\section{Prediction of rituximab and tocilizumab efficiency in rheumatoid arthritis}

\author{
M.V. Volkova \\ Belarusian medical Academy of postgraduate education, Minsk, Belarus
}

\begin{abstract}
Аннотация
Цель: изучить возможность прогнозирования эффективности лечения тоцилизумабом и ритуксимабом при ревматоидном артрите (РА) с учетом клинико-иммунологических особенностей пациентов.

Материал и методь. Проанализирована эффективность лечения тоцилизумабом у 53 пациентов и ритуксимабом у 22 пациентов с РА в течение 12 месяцев, оценена прогностическая роль исходных значений индексов активности, наличия системных проявлений, длительности РА, уровней аутоантител, острофазовых белков.

Результаты. Установлена высокая эффективность лечения моноклональными антителами при РА в исследуемой выборке, цели лечения достигли 84,91\% пациентов в группе тоцилизумаба и $72,72 \%$ в группе ритуксимаба, однако оставшиеся пациенты не достигли цели лечения через 12 месяцев наблюдения.

Выводы. Достоверными предикторами хорошего ответа на тоцилизумаб при РА могут служить высокая активность суставного синдрома, на ритуксимаб - серопозитивный вариант РА, а также наличие системных проявлений.
\end{abstract}

\section{Ключевые слова}

Ревматоидный артрит; тоцилизумаб; ритуксимаб; эффективность лечения; предикторы.

Конфликт интересов отсутствует.

\section{Введение}

Ревматоидный артрит (РА) является хроническим воспалительным заболеванием, характеризующимся припухлостью, болезненностью и деструкцией синовиальных суставов, которое приводит к тяжелой нетрудоспособности и преждевременной смертности [1].

В настоящее время лечение РА осуществляется согласно концепции «treat to target»[2]. Ле-

\begin{abstract}
Summary
Objective: to study the possibility of prediction the efficiency of treatment with tocilizumab and rituximab in rheumatoid arthritis (RA), taking into account the clinical and immunological characteristics of patients.

Material and methods. The efficacy of treatment with tocilizumab in 53 patients and rituximab in 22 patients with RA within 12 months was analyzed, the prognostic role of the initial values of activity indices, the presence of systemic manifestations, the duration of RA, levels of autoantibodies and acute phase proteins were evaluated.

Results. The high efficacy of treatment with biological drugs in RA was established, the treatment goals reached by $84.91 \%$ of patients in the group of tocilizumab and $72.72 \%$ in the group of rituximab, but the remaining patients did not reach the treatment goal after 12 months of follow-up.

Conclusions. Reliable predictors of a good response to tocilizumab in RA may be high activity of the joint syndrome, to rituximab - the seropositive variant of RA, as well as the presence of systemic manifestations.
\end{abstract}

\section{Keywords}

Rheumatoid arthritis, tocilizumab, rituximab, treatment efficacy, predictors.

There is no conflict of interest.

карственными средствами первой линии для лечения РА являются синтетические базисные противовоспалительные лекарственные средства (сБПЛС), которые должны назначаться всем пациентам немедленно после верификации диагноза. Золотым стандартом терапии сБПЛС остается метотрексат благодаря оптимальному сочетанию его эффективности и безопасности [2]. При недостаточной эффективности или 
плохой переносимости терапии сБПЛС каждые 3-6 месяцев терапия корректируется путем эскалации доз уже назначенных лекарственных средств, замены препаратов из группы сБПЛС или назначения биологических лекарственных средств (БЛС) [2]. Согласно рекомендациям ACR/EULAR при неэффективности сБПЛС и наличии факторов неблагоприятного прогноза следует назначить БЛС. Актуальные международные рекомендации по лечению РА не выделяют какое-либо БЛС в качестве препарата выбора в связи с их сходной эффективностью, установленной в клинических исследованиях [2]. Таким образом, выбор лекарственного средства осуществляется эмпирически. Это приводит к тому, что примерно $20-40 \%$ пациентов остаются неответчиками на лечение разными БЛС [3], до 40\% всех пациентов, получавших лечение БЛС, не достигают даже минимального улучшения [3]. Ситуация осложняется еще и тем, что пациенты получают последовательно несколько БЛС, что ведет к повышению стоимости, необоснованной токсичности и субоптимальной эффективности лечения [3].

В связи с этим требуется изучение клинических и лабораторных маркеров ответа на БЛС, а также расширение представлений о взаимном влиянии клинических и молекулярных маркеров на эффективность лечения.

Тоцилизумаб представляет собой рекомбинантное гуманизированное моноклональное антитело подкласса IgG1 к человеческому рецептору интерлейкина 6 (ИЛ-6), которое блокирует эффекты ИЛ-6: подавляет синтез иммуноглобулинов, активацию Т-клеток, выработку белков острой фазы воспаления в печени и гемопоэз, активацию остеокластов и др. [4]. Плейотропные провоспалительные эффекты ИЛ-6 при РА обусловливают высокую эффективность тоцилизумаба. [4]. В одном из мета-анализов [5] выявлено преимущество тоцилизумаба перед другими БЛС. Однако судить о преимуществах одного БЛС перед другими сложно ввиду ничтожно малого количества прямых «голова к голове» исследований эффективности БЛС между собой. В одном таком исследовании - ADACTA [6] - проводилось сравнение тоцилизумаба и адалимумаба. По его результатам ремиссии достигли 39,9\% пациентов, получавших тоцилизумаб и всего $10,4 \%$ пациентов, получавших адалимумаб. В других, уже непрямых исследованиях также продемонстрирована более высокая эффективность тоцилизумаба по сравнению с блокаторами фактора некроза опухоли альфа (ФНОа). Непосредственного сравнения эффективности тоцилизумаба и ритуксимаба в рандомизированных исследованиях не проводилось.

Ритуксимаб представляет собой химерное моноклональное антитело, связывающееся с поверхностным маркером CD20 на В-клетках. Действие препарата охватывает пре-В-клетки, зрелые В-клетки и В-клетки памяти. После связывания с ритуксимабом, В-клетки погибают вследствие запуска ряда механизмов, включающих антитело-зависимую клеточно-опосредованную цитотоксичность, комплемент-зависимую цитотоксичность и апоптоз [7]. При изучении возможных предикторов ответа на анти-В-клеточную терапию установлена хорошая эффективность ритуксимаба при серопозитивном РА, при значительном повышении АЦЦП и РФ (больше трех верхних границ норм) [5]. Положительный эффект анти-В-клеточной терапии ритуксимабом наблюдался у пациентов с васкулитом, кератитом, склеритом, легочными узелками и синдромом Фелти [8-10].

Целью работы стало исследование возможности прогнозирования эффективности лечения тоцилизумабом и ритуксимабом при РА с учетом клинико-иммунологических особенностей пациентов.

\section{Материалы и методы}

Исследование носит проспективный наблюдательный сплошной характер и основано на сборе сведений и заборе венозной крови до начала лечения БЛС и последующей оценке эффективности лечения через 6 и 12 месяцев лечения. В исследование включено 75 пациентов (69 женщин (92,00\%), 6 мужчин (8,00\%)) с достоверным диагнозом РA согласно критериям EULAR/ACR 2010 длительностью не менее 6 месяцев.

Общая характеристика пациентов приведена таблице 1.

В группе пациентов, которые получали тоцилизумаб, были выявлены следующие системные проявления: ревматоидные узелки - у $10(18,86 \%)$ пациентов, синдром Шегрена - у 1 (1,88\%) пациента, лихорадка - у 2 (3,76\%) пациентов, амиотрофия - у $1(1,88 \%)$ пациента.

В группе пациентов, которые получали ритуксимаб были выявлены следующие системные проявления: ревматоидные узелки - у 3 (13,63\%) пациентов, синдром Шегрена - у 2 (9,09\%) пациентов, лимфоаденопатия - у $1(4,54 \%)$ пациента, интерстициальные изменения легких - у 1 (4,54\%) пациента. 
Таблица 1. Основные показатели пациентов с ревматоидным артритом

\begin{tabular}{|c|c|c|}
\hline Показатель & $\begin{array}{l}\text { Пациенты, } \\
\text { получавшие тоцилизумаб }\end{array}$ & $\begin{array}{l}\text { Пациенты, } \\
\text { получавшие ритуксимаб }\end{array}$ \\
\hline Пол, ж/м, n & $50 / 3$ & $19 / 3$ \\
\hline Возраст, годы* & $45,5 \pm 11,79$ & $44,26 \pm 13,33$ \\
\hline Длительность заболевания, месяцы & $\begin{array}{l}\text { 115,00 } \\
\text { (95\%ДИ:71,31- 144,00) }\end{array}$ & $\begin{array}{l}98,00 \\
(95 \% Д И: 36,00-148,00)\end{array}$ \\
\hline \multicolumn{3}{|l|}{ Рентгенологическая стадия РА, n (\%) } \\
\hline I & $2(3,77 \%)$ & $2(9,09 \%)$ \\
\hline II & $24(45,28 \%)$ & $9(40,91 \%)$ \\
\hline III & $23(43,39 \%)$ & $11(50,00 \%)$ \\
\hline IV & $4(7,56 \%)$ & 0 \\
\hline Системные проявления, n (\%) & $11(20,75 \%)$ & $5(22,72 \%)$ \\
\hline DAS 28 & $6,69 \pm 1,20$ & $6,72 \pm 1,08$ \\
\hline SDAI & $27,52 \pm 17,01$ & $30,03 \pm 18,74$ \\
\hline CDAI & $27,50 \pm 15,87$ & $28,75 \pm 15,89$ \\
\hline РФ-позитивные, n (\%) & $37(69,81 \%)$ & $19(86,36 \%)$ \\
\hline РФ-негативные, n (\%) & $16(30,19 \%)$ & $3(13,64 \%)$ \\
\hline АЦЦП-позитивные, n (\%) & $39(73,58 \%)$ & $19(86,36 \%)$ \\
\hline АЦЦП-негативные, n (\%) & $14(26,42 \%)$ & $3(13,64 \%)$ \\
\hline \multicolumn{3}{|l|}{ Предшествующая терапия сБПЛС } \\
\hline Без базисной терапии & $5(9,43 \%)$ & 0 \\
\hline Метотрексат & $42(79,25 \%)$ & $20(90,90 \%)$ \\
\hline Доза метотрексата, мг/нед & $\begin{array}{l}15,00 \\
(95 \% Д И ~ 14,86-15,00)\end{array}$ & \\
\hline Сульфасалазин & $1(1,89 \%)$ & 0 \\
\hline Лефлуномид & $3(5,66 \%)$ & $1(4,55 \%)$ \\
\hline Гидроксихлорохин & 0 & $1(4,55 \%)$ \\
\hline Комбинированная терапия & $2(3,77 \%)$ & 0 \\
\hline $\begin{array}{l}\text { Пероральный прием ГК в дозе 4-8 мг/сутки, } \\
\text { n (\%) }\end{array}$ & $28(52,83 \%)$ & $11(50,00 \%)$ \\
\hline
\end{tabular}

АЦЦП - антитела к циклическому цитруллинированному пептиду; РФ- ревматоидный фактор; DAS28 - Disease activity score 28; SDAl -Simplified disease activity index, CDAl - clinical disease activity index

Исходно, через 3, 6 и 12 месяцев проводилась оценка клинических (число болезненных суставов (ЧБС), число припухших суставов (ЧПС), оценка активности заболевания пациентом и врачом по визуальной аналоговой шкале (ВАШ)) и лабораторных (С-реактивный белок (СРБ), скорость оседания эритроцитов (СОЭ)) показателей.

Тоцилизумаб внутривенно в дозе 8 мг/кг 1 раз в 4 недели внутривенно получали $16(30,18 \%)$ пациентов, подкожно в дозе 162 мг/0,9 мл 1 раз в неделю -37 (69,82\%) пациентов.

Ритуксимаб все пациенты получали в дозе 500 мг внутривенно - 2 инфузии с интервалом в 2 недели каждые 6 месяцев с проведением стандартной премедикации. Для оценки эффективности лечения использовали критерии EULAR [11], a также оценивали изменения индекса DAS28 через 3, 6 и 12 месяцев после первичного осмотра. Лечение считалось эффективным через 6 месяцев лечения у тех пациентов, которые достигли уровня DAS28<2,6 [12].

Уровни антител к циклическому цитруллинированному пептиду (АЦЦП) оценивали методом иммуноферментного анализа (ИФА) согласно инструкциям производителя тест-систем фирмы Euroimmun (Германия). Уровни ревматоидного фактора (РФ) оценивали методом кинетической нефелометрии на автоматическом анализаторе Beckman Coulter (USA). Наличие антинуклеарных антител (АНА) определяли методом непрямой иммунофлюоресценции (НИФ) согласно инструкциям производителя тест-систем фирмы Euroimmun (Германия), а также с использованием 
автоматизированной системы учета непрямой иммунофлюоресценции AKLIDES с использованием соответствующих реагентов фирмы Medipan (Германия).

Статистическая обработка данных осуществлялась с помощью программного обеспечения Statistica 7.0 (StatSoft, США) и Medcalc 12.5.0.0 (США), включая общепринятые методы параметрического и непараметрического анализа, ROC-анализ, логичтическую регрессию, точный критерий Фишера.

\section{Результаты и обсуждение}

Результаты наблюдения за пациентами, которые получали лечение тоцилизумабом представлены в таблице 2 .

Установлена высокая эффективность тоцилизумаба уже через 6 месяцев лечения. Было проведено сопоставление наличия определенных клинических (наличие системных проявлений, число припухших суставов (ЧПС) и число болезненных суставов (ЧБС)) и лабораторных признаков (уровень гемоглобина, СОЭ, СРБ, АЦЦП, РФ, АНА) и эффективности лечения. Из всех проанализированных показателей установлено, что лечение тоцилизумабом достоверно эффективно при наличии у пациента до начала лечения активного воспалительного процесса в суставах (ЧПС>7), (ROC-анализ, чувствительность 81,82\%, специфичность 44,44\%, площадь под кривой $0,722, \mathrm{p}=0,019)$. Учитывая то, что не установлено зависимости эффективности лечения от серопозитивности по РФ и АЦЦП, можно ожидать хорошего результата терапии тоцилизумабом как при серопозитивном, так и серонегативном РА.

Результаты наблюдения за пациентами при лечении ритуксимабом приведены в таблице 3 .

Было проведено сопоставление наличия определенных клинических (наличие системных проявлений, ЧБС, ЧПС) и лабораторных признаков (АЦЦП, РФ, АНА) и эффективности лечения. Установлено, что лечение ритуксимабом достоверно эффективно при положительном результате на РФ (точный критерий Фишера, $\mathrm{p}=0,017$ ), а также при системных проявлениях РА (ревматоидные узелки, синдром Шегрена, амиотрофия, положительный результат на АНА, точный критерий Фишера, $\mathrm{p}=0,014)$. Таким образом, при серопозитивном РА с системными проявлениями или наличием АНА лекарственным средством выбора может быть ритуксимаб.

Таким образом, в исследованной выборке пациентов подтверждается высокая эффективность комбинированной терапии БЛС и сБПЛС. Множество различных факторов оказывает влияние на эффективность лечения БЛС и все они должны приниматься во внимание при лечении каждого конкретного пациента. Исследования эффективности и безопасности БЛС, а также сравнительной эффективности БЛС дают лишь общую картину, не выделяют наиболее эффективные стратегии в зависимости от индивидуальных особенностей пациента. Персонализированный подход в лечении РА находится в начале своего формирования, требуется глубокая

Таблица 2. Активность ревматоидного артрита по DAS28 при лечении тоцилизумабом

\begin{tabular}{llll}
\hline Показатель & Исходно & Через 6 месяцев & Через 12 месяцев \\
\hline DAS28<2,6 (ремиссия) n (\%, пациентов) & 0 & $37(69,81)$ & $45(84,91)$ \\
DAS 28 2,6-3,2 (низкая активность), \% пациентов & 0 & $16(30,19)$ & $8(15,09)$ \\
$\begin{array}{l}\text { DAS 28 3,2-5,1 (умеренная активность), \% паци- } \\
\text { ентов }\end{array}$ & 0 & 0 & 0 \\
DAS 28>5,1 (высокая активность), \% пациентов & $53(100)$ & 0 & 0 \\
\hline
\end{tabular}

DAS28 - Disease activity score 28

Таблица 3. Активность ревматоидного артрита по DAS28 при лечении ритуксимабом

\begin{tabular}{llll}
\hline Показатель & Исходно & Через 6 месяцев & Через 12 месяцев \\
\hline DAS28<2,6 (ремиссия) n (\%, пациентов) & 0 & $14(63,63)$ & $16(72,72)$ \\
DAS 28 2,6-3,2 (низкая активность), \% пациентов & 0 & $8(36,37)$ & $6(27,28)$ \\
DAS 28 3,2-5,1 (умеренная активность), \% паци- & 0 & 0 & 0 \\
ентов & & 0 & 0 \\
DAS 28>5,1 (высокая активность), \% пациентов & $22(100)$ & 0 & 0 \\
\hline
\end{tabular}

DAS28 - Disease activity score 28 
методологическая и научная проработка проблемы, создание надежных средств для оценки индивидуальной эффективности того или иного препарата даже у небольшой подгруппы пациентов с определенным эндотипом. В настоящем исследовании установлена возможность прогнозирования эффективности БЛС в зависимости от клинико-иммунологических особенностей пациента, данный подход не несет материальных затрат, не отнимает времени и сил врача, однако может помочь сделать выбор БЛС обоснованным, обратить более пристальное внимание на особенности пациента в динамике лечения, открыть новые закономерности клинического течения РА при применении конкретного БЛС.

\section{Литература}

1. Aletaha D, Neogi T, Silman AJ et al. 2010 Rheumatoid arthritis classification criteria: an American College of Rheumatology / European League Against Rheumatism collaborative initiative. Arthritis Rheum. 2010; 62(9): 2569-2581. DOI: 10.1002/ art.27584.

2. Smolen JS, Landewé R, Bijlsma J et al. EULAR recommendations for the management of rheumatoid arthritis with synthetic and biological disease-modifying antirheumatic drugs: 2016 update. Ann Rheum Dis. 2017; 76(6):1-18. DOI: 10.1136/annrheumdis-2016-210715

3. Nam JL, Takase-Minegishi K, Ramiro S et al. Efficacy of biological disease-modifying antirheumatic drugs: a systematic literature review informing the 2013 update of the EULAR recommendations for the management of rheumatoid arthritis / J.L. Nam, S. Ramiro, C. Gaujoux-Viala et al. Ann Rheum Dis. 2017;76(6);1113-1136. DOI: 10.1136/annrheumdis-2016-210713

4. Singh JA, Beg S, Lopez-Olivo MA. Tocilizumab for rheumatoid arthritis: a Cochrane systematic review J. Rheumatol. 2011;38(1):10-20. DOI: 10.3899/jrheum.100717

5. Alfonso-Cristancho R, Armstrong N, Arjunji R. et al. Comparative effectiveness of biologics for the management of rheumatoid arthritis: systematic review and network metaanalysis. Clin Rheumatol. 2017; 36(1):25-34. DOI: 10.1007/ s10067-016-3435-2.

6. Gabay C, Emery P, van Vollenhoven R et al. Tocilizumab monotherapy versus adalimumab monotherapy for treatment of rheumatoid arthritis (ADACTA): a randomised, double-blind,

\section{Выводы}

1. Установлена хорошая эффективность лечения тоцилизумабом и ритуксимабом при РА в исследуемой выборке, однако у 15,09\% и 27,08\% пациентов не достигнута цель лечения через 12 месяцев наблюдения.

2. В качестве предиктора ответа на тоцилизумаб при РА может служить высокая активность суставного синдрома (ЧПС больше 7).

3. Высокую эффективность ритуксимаба можно ожидать при серопозитивном по РФ варианте РА, а также при наличии системных проявлений (ревматоидные узелки, синдром Шегрена, амиотрофия, положительный результат на AHA).

controlled phase 4 trial. Lancet. 2013;4;381(9877):1541-1550. DOI: $10.1016 /$ S0140-6736(13)60250-0

7. Smith MR. Rituximab (monoclonal anti-CD20 antibody): mechanisms of action and resistance. Oncogene. 2003;22:73597368 .

8. Assmann G, Pfreundschuh M, Voswinkel J. Rituximab in patients with rheumatoid arthritis and vasculitis-associated cutaneous ulcers. Clin Exp Rheumatol. 2010;28(1 Suppl 57):8183.

9. Chandra PA, Margulis Y, Schiff C. Rituximab is useful in the treatment of Felty's syndrome. Am J Ther. 2008;15(4):321-322. DOI: 10.1097/MJT.0b013e318164bf32.

10. Iaccheri B, Androudi S, Bocci EB et al. Rituximab treatment for persistent scleritis associated with rheumatoid arthritis. Ocul Immunol Infamm. 2010;18(3):223-225. DOI: $10.3109 / 09273941003739928$.

11. Felson DT, Smolen JS, Wells G et al. American College of Rheumatology / European League Against Rheumatism provisional definition of remission in rheumatoid arthritis for clinical trials. Arthritis Rheum. 2011; 63(3):573-586. DOI: 10.1002/art.30129.

12. Prevoo ML, van 't Hof MA, Kuper HH et al. Modified disease activity scores that include twenty-eight-joint counts. Development and validation in a prospective longitudinal study of patients with rheumatoid arthritis Arthritis Rheum. 1995; 38(1):44-48.

\section{Сведения об авторе:}

Волкова Маргарита Васильевна - к.м.н., докторант кафедры кардиологии и ревматологии государственного учреждения образования «Белорусская медицинская академия последипломного образования».

Корреспондентский почтовый адрес: 210013, г. Минск, ул. П.Бровки, 3/1, к. 706.

Адрес электронной почты margovolkova@gmail.com

Контактный номер телефона +375 447773900

Личный идентификатор ORCID 0000-0001-8572-9252

Поступила 20.06.2019 г. 